\title{
A 90-Day Inhalation Toxicity Study of Ethyl Formate in Rats
}

\author{
Mi Ju Lee and Hyeon-Yeong Kim \\ Department of Pathology, Inhalation Toxicity Research Center, Chemicals Toxicity Research Bureau, \\ Occupational Safety and Health Research Institute, Korea Occupational Safety and Health Agency, Daejeon, Korea
}

\begin{abstract}
Ethyl formate, a volatile solvent, has insecticidal and fungicidal properties and is suggested as a potential fumigant for stored crop and fruit. Its primary contact route is through the respiratory tract; however, reliable repeated toxicological studies focusing on the inhalation route have not been published to date. Therefore, the present study was conducted to investigate the safety of a 90-day repeated inhalation exposure in rats. Forty male and 40 female rats were exposed to ethyl formate vapor via inhalation at concentrations of $0,66,330$, and 1,320 ppm for $6 \mathrm{hr} /$ day, 5 days a week for 13 weeks. Clinical signs, body weights, food consumption, urinalysis, hematologic parameters, serum chemistry measurements, organ weights, necropsy, and histopathological findings were compared between the control and ethyl formate-exposed groups. Locomotor activity decreased during exposure and recovered afterward in male and female rats exposed to $1,320 \mathrm{ppm}$ ethyl formate. Body weight and food consumption continuously decreased in both sexes exposed to $1,320 \mathrm{ppm}$ ethyl formate from week 1 or 3 compared with the control values. The increases in adrenal weight and decreases in thymus weight were noted in both sexes exposed to ethyl formate at 1,320 ppm. Degeneration, squamous metaplasia of olfactory epithelium in the nasopharyngeal tissue, or both were noted in the male and female rats at $1,320 \mathrm{ppm}$ and female rats at $330 \mathrm{ppm}$ ethyl formate. Taken together, our results indicate that ethyl formate-induced changes were not observed in male and female rats at 330 and $66 \mathrm{ppm}$, respectively. This indicates that exposure to ethyl formate at concentrations below $66 \mathrm{ppm}$ for 90 days is relatively safe in rats. This is the first report of a full-scale repeated inhalation toxicity assessment in rats and could contribute to controlling occupational environmental hazards related to ethyl formate.
\end{abstract}

Key words: Ethyl formate, 90-day repeated inhalation toxicity, Occupational health

\begin{abstract}
Correspondence to: Hyeon-Yeong Kim, Department of Pathology, Inhalation Toxicity Research Center, Chemicals Toxicity Research Bureau, Occupational Safety and Health Research Institute, Korea Occupational Safety and Health Agency, 30, Expo-ro 339beon-gil, Yuseong-gu, Daejeon 34122, Korea

E-mail: 1989135@kosha.or.kr
\end{abstract}

Abbreviations: Alb, albumin; ALP, alkaline phosphatase; ALT, alanine aminotransferase; APTT, activated partial thromboplastin time; AST, aspartate aminotransferase; BUN, blood urea nitrogen; Crea, creatinine; $\mathrm{HCT}$, hematocrit; $\mathrm{HGB}$, hemoglobin; $\mathrm{MCH}$, mean cell hemoglobin; $\mathrm{MCHC}$, mean cell hemoglobin concentration; MCV, mean cell volume; OEL, occupational exposure limit; PLT, platelet; PT, prothrombin time; RBC, red blood cell; Reti, reticulocyte; T-Bili, total bilirubin; T-Chol, total cholesterol; TG, triglyceride; TP, total protein; WBC, white blood cell.

This is an Open-Access article distributed under the terms of the Creative Commons Attribution Non-Commercial License (http:// creativecommons.org/licenses/by-nc/3.0) which permits unrestricted non-commercial use, distribution, and reproduction in any medium, provided the original work is properly cited.

\section{INTRODUCTION}

Many fruits and vegetables produce ethyl formate, which is also found in most plant and animal-based product, such as beer, wine, tuna, cheese, and bread $(1,2)$. Ethyl formate is an important flavoring and aroma component of fruits and vegetables and has been revealed to have insecticidal and fungicidal properties (3). Based on these characteristics, it has been used as a fumigant for grains, but is currently restricted to dried fruit and processed cereal products (4). However, it has been suggested as a potential fumigant for stored crops and fruit (5-7), and commercial products have been developed as a postharvest treatment for horticulture and stored grains (2). Ethyl formate is a nonchlorinated solvent, which has been used to prepare poly-D,L-lactide-co-glycolide (PLGA) microspheres using spray drying (8). It is also used as a flavoring for lemonade and essences, a solvent for nitrocellulose, and in organic 
synthesis (9).

Occupational exposure limits (OELs) are the maximum acceptable air concentrations of a hazardous substance above which it is not safe for a worker to be exposed. The current OEL of ethyl formate in the Republic of Korea, the US, England, Germany, Denmark, and the Netherlands is $100 \mathrm{ppm}\left(300 \mathrm{mg} / \mathrm{m}^{3}\right), 8-\mathrm{hr}$ time-weighted average (TWA) (9-11). Setting OELs is complicated and requires considerable animal and human toxicological data $(12,13)$. The most important information for setting an OEL is human toxicity data. Exposure to $\geq 330 \mathrm{ppm}$ ethyl formate in humans was reported to be slightly irritating to the eyes and nose, but the significance of this finding could not be assessed because of the limited reporting (9). The animal toxicity of ethyl formate has been revealed in acute toxicity studies by exposure via inhalation, dermal, and oral routes, and repeated toxicity studies using feeding and intraperitoneal routes $(9,14,15)$. Considering the volatility of ethyl formate, administration through dermal and oral routes as well as feeding would not be appropriate methods. No reliable repeated toxicological studies focusing on the inhalation route have been published to date, although inhalation is the primary route of exposure to ethyl formate in contact workers.

Long-term and low-level exposure to a chemical in an industrial field could cause conflicts between workers and employers in cases of unpredicted health problems and deficient scientific evidence. Anxiety persists in workers who endure long-term and low-level exposure. OEL and reported toxicity results are insufficient for resolving this problem. Therefore, in this study, the safety of a 90-day repeated inhalation exposure in rats was investigated.

\section{MATERIALS AND METHODS}

Animal husbandry and maintenance. Forty-eight 6week-old Sprague-Dawley rats of each sex were obtained from a specific pathogen-free colony at Japan SLC., Inc. (Hamamatsu, Japan) via Joongang Experimental Animal Co., Ltd. (Seoul, Korea) and used after 1-week quarantine and acclimatization. The rats were housed in a room maintained at a temperature of $22 \pm 3{ }^{\circ} \mathrm{C}$ under a relative humidity of $50 \pm 20 \%$ with artificial lighting from 08:00 to 20:00 and 12 15 air changes/hr. They were housed individually in wire-bottomed stainless-steel mesh cages placed in exposure chambers and provided sterilized tap water and commercial rodent chow (PicoLab Rodent Diet 5053, LabDiet, USA) ad libitum. The Institutional Animal Care and Use Committee of the Inhalation Toxicity Research Center approved the protocols used in this study.

Test chemical and exposure. Ethyl formate was purchased from Acros Organic (Geel, Belgium). Whole-body exposure chambers (WITC-00-M, HCT Co., Korea) includ- ing a liquid vapor generator (LVg-04-A, HCT Co.) were used to expose the rats to ethyl formate. The test rats were exposed to either ethyl formate or fresh air for $6 \mathrm{hr} /$ day, 5 days a week for 90 days. The inhalation exposure was carried out from 10:00 to 16:00 in the stainless-steel cage of the exposure chamber. The experimental design was established based on the usual schedule of workers, as well as the major exposure route of the test chemical.

Chamber condition. The temperature, relative humidity, pressure, and air ventilation in the chambers were recorded using an environmental controller (ITC manager, HCT Co.). The concentrations of ethyl formate in the chambers were calibrated to $49.6,298$, and 1,792 ppm ethyl formate standard gas (RI-GAS, Korea). The ethyl formate levels were detected using gas chromatography (TRACE1310, Thermo Scientific, China) with the following apparatus: detector, flame ionization detector; column, TraceGold TG5MS 5\% diphenyl-95\% dimethyl polysiloxane capillary column (30 m length, $0.25 \mathrm{~mm}$ i.d., $0.25 \mathrm{~mm}$ film thickness). The conditions used were: detector, oven, and injector temperatures, 250,100 , and $130^{\circ} \mathrm{C}$, respectively and formate to generate ethyl formate vapor-air mixture. Following airflow containing saturated ethyl formate was conditioned at $23^{\circ} \mathrm{C}$ by passing it through a thermostat-controlled condenser, and then diluted with a large volume of fresh air. Finally, the diluted vapor-air mixture was supplied to the inhalation exposure chambers. The ethyl formate vapor concentrations in the chambers were measured every $20 \mathrm{~min}$ during exposure and controlled within $\pm 10.7,0.3$, and $2 \%$ of the target concentration in the low-, mid-, high-dose groups, respectively. The mean concentration measured every $20 \mathrm{~min}$ for $6 \mathrm{hr}$ was considered as the concentration value for each day. This was then averaged over the 90-day exposure period to obtain the mean and standard deviations. The daily vapor concentrations in the three chambers were $66.4 \pm 2.05,331.1 \pm 6.19$, and $1345.8 \pm 24.3 \mathrm{ppm}$, respectively.

Experimental groups. Forty male and 40 female rats were randomly assigned to the following four groups and treated with the indicated doses: control $(0 \mathrm{mg} / \mathrm{L})$, low-dose $(0.2 \mathrm{mg} / \mathrm{L}, 66 \mathrm{ppm})$, mid-dose (1 mg/L, $330 \mathrm{ppm})$, and highdose $(4 \mathrm{mg} / \mathrm{L}, 1,320 \mathrm{ppm})$ groups. The control group was exposed to fresh air only. Concentrations of 66,330 , and $1,320 \mathrm{ppm}$ were selected based on a prior study $(9,14,15)$ and the OEL.

Animal observation. All the rats were weighed individually on the first exposure day and once a week after that. The body weight data from the necropsy day were not included in the evaluation of body weight because these data reflected the fasting body weight of the rats. All rats were observed before, during, and after the exposure period 
for mortality, general condition, and clinical signs. Daily food consumption was measured before the initiation of exposure and once a week after that. Food consumption was calculated by subtracting the amount of leftover feed from the total feed provided.

Ophthalmoscopy. All rats underwent an ophthalmic examination on week 12. The ophthalmic examination was performed after the administration of mydriatic ocutropic ophthalmic drops (Mydriacyl ${ }^{\circledR}$ eye drops 1\%, Alcon Korea, Seoul, Korea), using a nonmydriatic eye fundus camera (VeraCamTM DS-10, Nidek, Gamagori, Japan) and slitlamp biomicroscopy (KOWA ${ }^{\circledR}$ SL-15, Kowa Co. Ltd., Tokyo, Japan).

Urinalysis. The urinalysis was performed for five rats in each group on week 13 of exposure. Fresh urine (sampled within approximately $3 \mathrm{hr}$ of urine excretion) was collected and the $\mathrm{pH}$, protein, glucose, ketone body, bilirubin, occult blood, leukocyte, nitrite, urobilinogen, and specific gravity were determined using a urine analyzer (Clinitek Advantus, Siemens, Germany) or test kits (Multistix 10 SG, Siemens).

Hematology and serum chemistry. On day 90 , the rats were fasted overnight and anesthetized the following day with isoflurane prior to being euthanized. Blood $(10 \mathrm{~mL})$ was collected via the abdominal aorta. Blood samples (approximately $2 \mathrm{~mL}$ ) for hematology were placed in a vacutainer containing EDTA. Then, approximately $2.7 \mathrm{~mL}$ of blood mixed with $3.2 \%$ sodium citrate was centrifuged at $3,000 \mathrm{rpm}$ for $10 \mathrm{~min}$ to measure prothrombin time (PT) and activated partial thromboplastin time (APTT). Blood samples in a vacutainer for blood chemistry were centrifuged at 3,000 rpm for $10 \mathrm{~min}$ to obtain serum within $1 \mathrm{hr}$ after collection.

Hematology measurements performed were the total red blood cell (RBC) count, hemoglobin (HGB) concentration, hematocrit (HCT), mean cell volume (MCV), mean cell hemoglobin $(\mathrm{MCH})$, mean cell hemoglobin concentration (MCHC), platelet (PLT) count, total white blood cell (WBC) count, differential WBC count (neutrophil, lymphocyte, monocyte, eosinophil, and basophil), reticulocyte (Reti) count, PT, and APTT using the ADVIA 2120i (Siemens) or ACL ELITE systems (Instrumentation Laboratory, USA).

The serum biochemistry parameters analyzed were alanine aminotransferase (ALT), aspartate aminotransferase (AST), alkaline phosphatase (ALP), blood urea nitrogen (BUN), creatinine (Crea), total bilirubin (T-Bili), total protein (TP), albumin (Alb), A/G ratio, total cholesterol (T$\mathrm{Chol}$ ), triglyceride (TG), glucose (Glu), potassium (K), calcium $(\mathrm{Ca})$, chloride $(\mathrm{Cl})$, inorganic phosphorus $(\mathrm{P})$, and sodium $(\mathrm{Na})$ using the TBA-120FR automated clinical analyzer (Toshiba Co., Japan).
Necropsy, organ weight, and histopathological examination. Following blood sample collection, all rats underwent a complete necropsy, which consisted of examinations of the external body surfaces and all orifices, as well as the cranial, thoracic, and abdominal cavities and their contents. The following organs were trimmed and weighed: the adrenals, brain, heart, kidneys, liver, spleen, testes, thymus, epididymides, lung, thyroids, ovaries, and uterus. Organ-to-body weight ratios were calculated for each of these organs. The following organ/tissues were preserved in $10 \%$ neutral buffered formalin: the adrenals, aorta, bone marrow, brain, cecum, colon, duodenum, epididymides, esophagus, eyes, femur, Harderian glands, heart, ileum, jejunum, kidneys, larynx, liver, lung, lymph nodes (hilar and mesenteric), mammary gland, nasopharyngeal tissue, nerves (optic and sciatic), pancreas, parathyroids, pituitary, prostate, rectum, salivary glands (submandibular, sublingual, and parotid), seminal vesicles, skeletal muscle, skin, spinal cord (cervical, lumbar, and thoracic), spleen, sternum, stifle joint, stomach, testes, teeth, thymus, thyroids, trachea, urinary bladder, ovaries, and uterus. The eyes/optic nerve and testes were preserved in Davidson's solution. All the preserved tissues from rats exposed to 0 and $1,320 \mathrm{ppm}$ ethyl formate were paraffin-embedded, sectioned, stained with hematoxylin and eosin, and then examined microscopically. In addition, nasopharyngeal tissue from rats exposed to 66 and $330 \mathrm{ppm}$ was histopathologically evaluated because ethyl formate-related change was noted at $1,320 \mathrm{ppm}$.

Statistical analysis. Statistical analysis was performed for body weight, food consumption, hematology and serum biochemistry parameters, organ weights, and organ/body weight. For the control and ethyl formate-exposed groups, the homogeneity of the variance of numerical data was determined using Levene's test. Groups with homogenous and heterogeneous data were compared using one-way analysis of variance (ANOVA) and non-parametric Kruskal-Wallis test, respectively. If statistical significance was observed $(p<0.05)$, Dunnett's test (for ANOVA) or the Steel test (for Kruskal-Wallis) was used for multiple comparisons of the control group with each dose group.

\section{RESULTS}

Clinical signs, body weight and food consumption. No animal mortality occurred during this study. The locomotor activity of the male and female rats decreased during exposure to 1,320 ppm ethyl formate but recovered after the exposure ended. Food consumption significantly decreased in male and female rats exposed to $1,320 \mathrm{ppm}$ ethyl formate from week 1 and week 3 , respectively, compared with that of the control rats (Fig. 1). Body weight gain significantly decreased in male and female rats exposed to 1,320 ppm ethyl formate from week 1 compared with that of the 

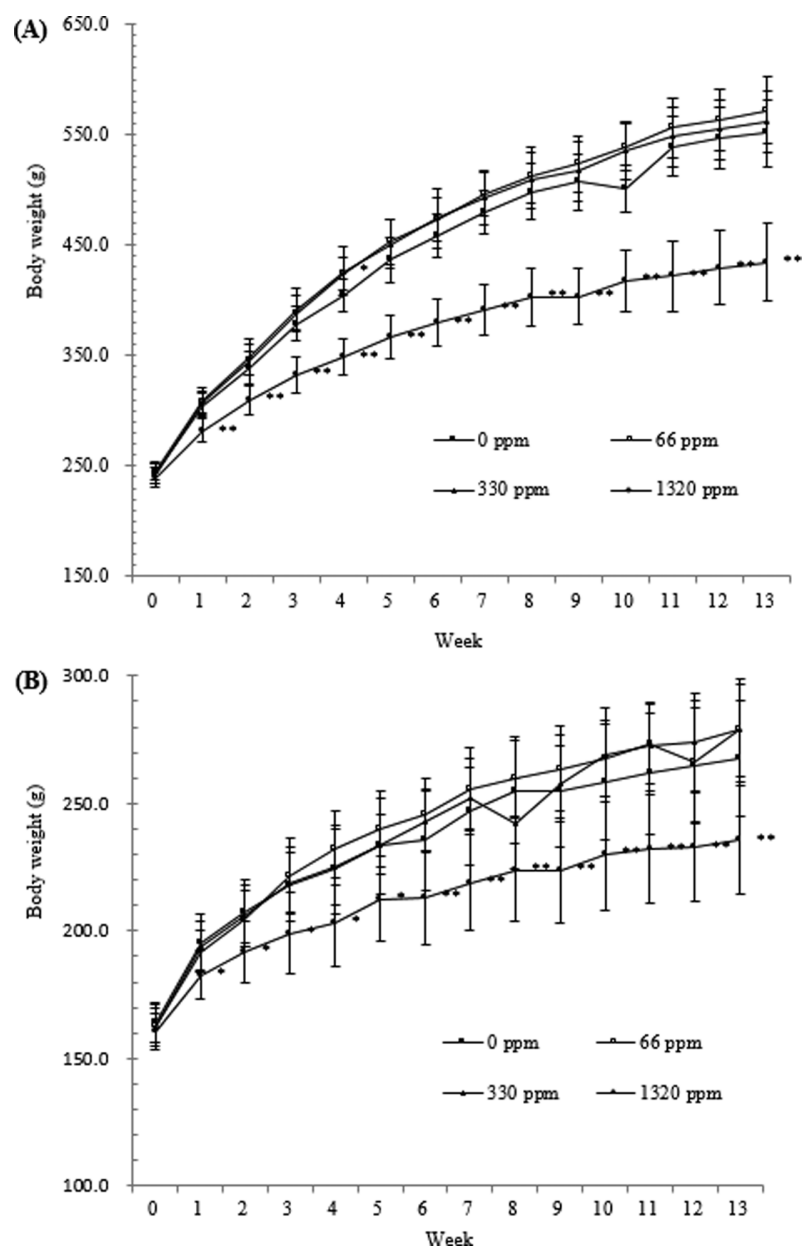

Fig. 1. Changes in body weight in (A) male and (B) female rats exposed to ethyl formate over time. Body weight was measured weekly for 13 weeks. Black squares, blank squares, triangles, and circles indicated mean values of $0,66,330$, and 1,320 ppm ethyl formate groups, respectively. ${ }^{*} p<0.05$ and ${ }^{* *} p<0.01$.

control rats (Fig. 1). Male rats exposed to $330 \mathrm{ppm}$ ethyl formate showed increased body weight gain on week 4 compared with that of the control group (Fig. 2).

Urinalysis. Ketone body ( $15 \mathrm{mg} / \mathrm{dL})$ levels above control values were detected in rats of both sexes exposed to 1,320 ppm and in female rats exposed to $330 \mathrm{ppm}$ ethyl formate. Urobilinogen $(1 \mathrm{mg} / \mathrm{dL})$ levels above control values were detected in male rats exposed to $1,320 \mathrm{ppm}$ ethyl formate.

Hematology. The hematological parameters analyzed are shown in Table 1. HGB and HCT increased in male rats that inhaled $1,320 \mathrm{ppm}$ ethyl formate $(p<0.01)$. Reti decreased in female rats that inhaled 1,320 ppm ethyl formate $(p<0.01)$.

Serum chemistry. The serum biochemistry parameters are shown in Table 2. Ca and TG levels decreased in male
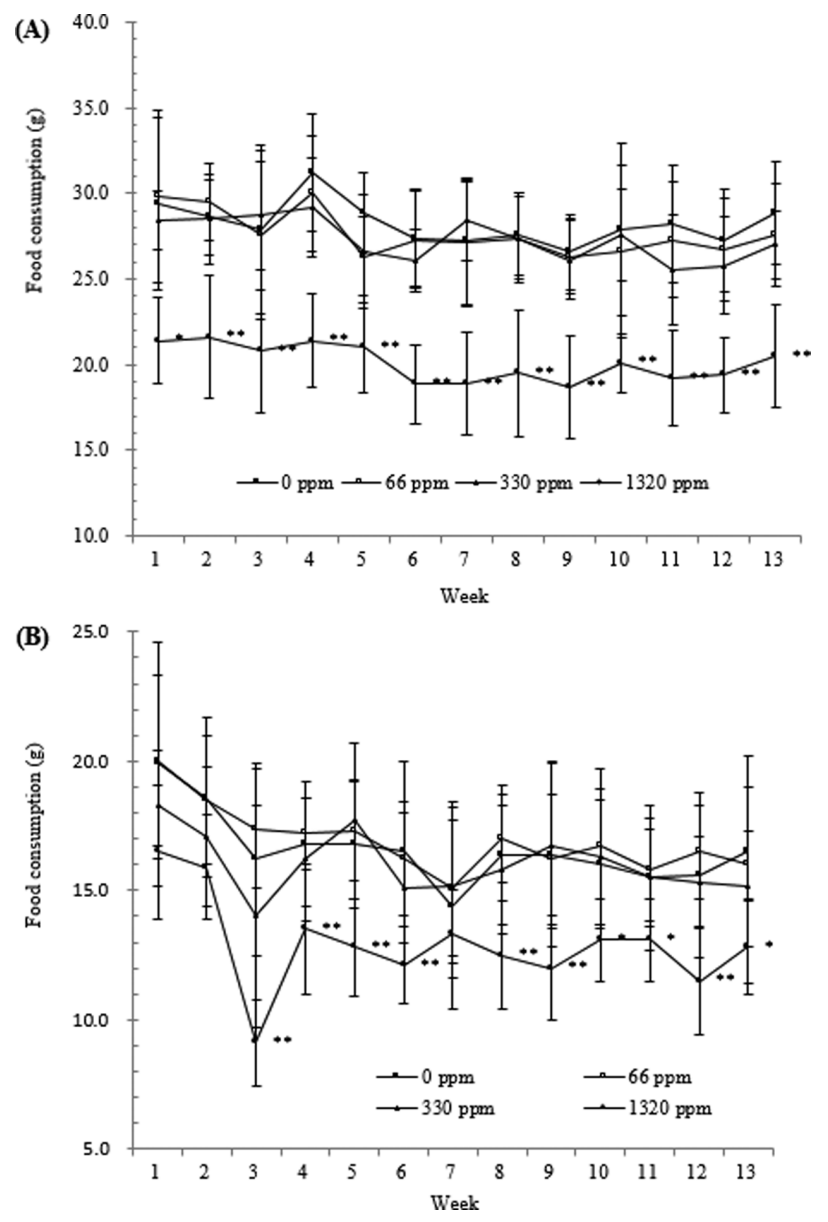

Fig. 2. Changes in food consumption of (A) male and (B) female rats exposed to ethyl formate over time. Food consumption was calculated weekly for 13 weeks. Black squares, blank squares, triangles, and circles indicated the mean values of $0,66,330$, and $1,320 \mathrm{ppm}$ ethyl formate groups, respectively. ${ }^{*} p<0.05$ and ${ }^{* *} p<0.01$.

and female rats exposed to ethyl formate at $1,320 \mathrm{ppm}$, respectively $(p<0.01)$.

Organ weight. The organ weights are shown in Table 3. The absolute and relative adrenal weight increased in male and female rats exposed to ethyl formate at $1,320 \mathrm{ppm}$ compared with the value in the control group (absolute of male: $p<0.05$, others: $p<0.01$ ). The absolute or relative thymus weight or both decreased in male and female rats exposed to ethyl formate at 1,320 ppm compared with values in the control rats (absolute of male: $p<0.01$, absolute and relative of female: $p<0.01$ ).

The absolute heart, kidney, liver, lung, and spleen weights decreased in male and female rats exposed to $1,320 \mathrm{ppm}$ ethyl formate. The relative brain, kidney, and lung weights increased in male and female rats exposed to $1,320 \mathrm{ppm}$ ethyl formate. 
Table 1. Hematology results of rats exposed to ethyl formate

\begin{tabular}{|c|c|c|c|c|}
\hline \multirow{2}{*}{$\begin{array}{l}\text { Parameter } \\
\text { (units of measure) }\end{array}$} & \multicolumn{4}{|c|}{ Concentration (ppm) } \\
\hline & 0 & 66 & 330 & 1320 \\
\hline \multicolumn{5}{|l|}{ Male } \\
\hline No. of animals & 10 & 10 & 10 & 10 \\
\hline $\operatorname{WBC}\left(10^{3} / \mu \mathrm{L}\right)$ & $6.55 \pm 1.26$ & $7.41 \pm 1.37$ & $7.02 \pm 1.55$ & $6.33 \pm 1.38$ \\
\hline \multicolumn{5}{|l|}{ WBC differential count } \\
\hline Neutrophil $\left(10^{3} / \mu \mathrm{L}\right)$ & $1.64 \pm 0.36$ & $2.12 \pm 1.38$ & $1.64 \pm 0.25$ & $1.55 \pm 0.35$ \\
\hline Lymphocyte $\left(10^{3} / \mu \mathrm{L}\right)$ & $4.51 \pm 1.01$ & $4.82 \pm 0.96$ & $4.93 \pm 1.25$ & $4.44 \pm 1.16$ \\
\hline Monocyte $\left(10^{3} / \mu \mathrm{L}\right)$ & $0.15 \pm 0.03$ & $0.19 \pm 0.06$ & $0.19 \pm 0.06$ & $0.13 \pm 0.02$ \\
\hline Eosinophil $\left(10^{3} / \mu \mathrm{L}\right)$ & $0.12 \pm 0.03$ & $0.14 \pm 0.03$ & $0.13 \pm 0.04$ & $0.13 \pm 0.03$ \\
\hline Basophil $\left(10^{3} / \mu \mathrm{L}\right)$ & $0.05 \pm 0.02$ & $0.05 \pm 0.02$ & $0.06 \pm 0.02$ & $0.05 \pm 0.02$ \\
\hline Neutrophil (\%) & $25.33 \pm 6.03$ & $27.40 \pm 12.18$ & $24.04 \pm 3.69$ & $24.74 \pm 4.29$ \\
\hline Lymphocyte (\%) & $68.44 \pm 6.20$ & $66.20 \pm 12.04$ & $69.48 \pm 3.75$ & $69.72 \pm 4.38$ \\
\hline Monocyte (\%) & $2.40 \pm 0.44$ & $2.51 \pm 0.66$ & $2.65 \pm 0.67$ & $2.00 \pm 0.40$ \\
\hline Eosinophil (\%) & $1.81 \pm 0.37$ & $1.92 \pm 0.52$ & $2.83 \pm 2.93$ & $2.07 \pm 0.61$ \\
\hline Basophil (\%) & $0.68 \pm 0.18$ & $0.70 \pm 0.18$ & $0.77 \pm 0.23$ & $0.76 \pm 0.33$ \\
\hline $\operatorname{RBC}\left(10^{6} / \mu \mathrm{L}\right)$ & $8.44 \pm 0.27$ & $8.45 \pm 0.31$ & $8.52 \pm 0.23$ & $8.78 \pm 0.37$ \\
\hline $\operatorname{HGB}(\mathrm{g} / \mathrm{dL})$ & $15.15 \pm 0.53$ & $15.36 \pm 0.47$ & $15.18 \pm 0.53$ & $16.16 \pm 0.48^{* *}$ \\
\hline $\operatorname{HCT}(\%)$ & $48.91 \pm 2.44$ & $50.06 \pm 1.85$ & $50.05 \pm 1.75$ & $52.26 \pm 2.32 * *$ \\
\hline MCV (fL) & $57.91 \pm 1.70$ & $59.36 \pm 3.11$ & $58.80 \pm 2.21$ & $59.58 \pm 2.13$ \\
\hline $\mathrm{MCH}(\mathrm{pg})$ & $17.96 \pm 0.40$ & $18.21 \pm 0.83$ & $17.83 \pm 0.51$ & $18.42 \pm 0.72$ \\
\hline $\operatorname{MCHC}(\mathrm{g} / \mathrm{dL})$ & $31.05 \pm 1.19$ & $30.69 \pm 0.88$ & $30.34 \pm 0.49$ & $30.95 \pm 1.01$ \\
\hline $\operatorname{PLT}\left(10^{3} / \mu \mathrm{L}\right)$ & $807.1 \pm 97.7$ & $823.1 \pm 80.2$ & $868.5 \pm 101.6$ & $745.7 \pm 92.8$ \\
\hline $\operatorname{Reti}\left(10^{3} / \mu \mathrm{L}\right)$ & $188.9 \pm 21.2$ & $217.5 \pm 34.2$ & $209.2 \pm 32.0$ & $165.1 \pm 40.0$ \\
\hline Reti $(\%)$ & $2.24 \pm 0.26$ & $2.57 \pm 0.37$ & $2.43 \pm 0.43$ & $1.88 \pm 0.46$ \\
\hline PT $(\mathrm{sec})$ & $10.89 \pm 0.54$ & $11.44 \pm 1.34$ & $11.06 \pm 1.03$ & $10.70 \pm 0.62$ \\
\hline APTT (sec) & $18.66 \pm 3.91$ & $17.18 \pm 1.48$ & $17.02 \pm 1.68$ & $17.50 \pm 1.99$ \\
\hline \multicolumn{5}{|l|}{ Female } \\
\hline No. of animals & 10 & 10 & 10 & 10 \\
\hline $\mathrm{WBC}\left(10^{3} / \mu \mathrm{L}\right)$ & $5.04 \pm 1.38$ & $4.82 \pm 1.21$ & $5.08 \pm 1.14$ & $4.66 \pm 1.20$ \\
\hline \multicolumn{5}{|l|}{ WBC differential count } \\
\hline Neutrophil $\left(10^{3} / \mu \mathrm{L}\right)$ & $1.15 \pm 0.32$ & $1.21 \pm 0.36$ & $1.25 \pm 0.53$ & $1.04 \pm 0.23$ \\
\hline Lymphocyte $\left(10^{3} / \mu \mathrm{L}\right)$ & $3.62 \pm 1.11$ & $3.35 \pm 0.92$ & $3.58 \pm 0.76$ & $3.39 \pm 0.97$ \\
\hline Monocyte $\left(10^{3} / \mu \mathrm{L}\right)$ & $0.12 \pm 0.05$ & $0.12 \pm 0.05$ & $0.11 \pm 0.06$ & $0.08 \pm 0.03$ \\
\hline Eosinophil $\left(10^{3} / \mu \mathrm{L}\right)$ & $0.09 \pm 0.04$ & $0.09 \pm 0.03$ & $0.10 \pm 0.05$ & $0.10 \pm 0.03$ \\
\hline Basophil $\left(10^{3} / \mu \mathrm{L}\right)$ & $0.01 \pm 0.01$ & $0.01 \pm 0.01$ & $0.01 \pm 0.00$ & $0.01 \pm 0.00$ \\
\hline Neutrophil (\%) & $23.03 \pm 5.15$ & $25.01 \pm 5.47$ & $24.14 \pm 6.91$ & $22.85 \pm 4.06$ \\
\hline Lymphocyte (\%) & $71.51 \pm 5.65$ & $69.59 \pm 6.24$ & $71.08 \pm 7.41$ & $72.12 \pm 4.20$ \\
\hline Monocyte (\%) & $5.59 \pm 10.70$ & $2.52 \pm 0.82$ & $1.98 \pm 0.69$ & $1.78 \pm 0.35$ \\
\hline Eosinophil (\%) & $1.82 \pm 0.43$ & $1.89 \pm 0.42$ & $1.84 \pm 0.69$ & $2.26 \pm 0.61$ \\
\hline Basophil (\%) & $0.17 \pm 0.09$ & $0.13 \pm 0.07$ & $0.21 \pm 0.09$ & $0.13 \pm 0.08$ \\
\hline $\mathrm{RBC}\left(10^{6} / \mu \mathrm{L}\right)$ & $8.15 \pm 0.56$ & $8.02 \pm 0.31$ & $8.23 \pm 0.26$ & $8.36 \pm 0.26$ \\
\hline $\operatorname{HGB}(\mathrm{g} / \mathrm{dL})$ & $15.52 \pm 0.69$ & $15.48 \pm 0.55$ & $15.86 \pm 0.42$ & $16.08 \pm 0.51$ \\
\hline HCT $(\%)$ & $43.57 \pm 1.86$ & $43.46 \pm 1.45$ & $44.48 \pm 0.93$ & $44.76 \pm 1.41$ \\
\hline MCV (fL) & $53.52 \pm 1.60$ & $54.21 \pm 0.96$ & $54.09 \pm 0.95$ & $53.58 \pm 1.49$ \\
\hline $\mathrm{MCH}(\mathrm{pg})$ & $19.09 \pm 0.64$ & $19.30 \pm 0.51$ & $19.29 \pm 0.40$ & $19.25 \pm 0.59$ \\
\hline $\mathrm{MCHC}(\mathrm{g} / \mathrm{dL})$ & $35.67 \pm 0.62$ & $35.59 \pm 0.55$ & $35.68 \pm 0.58$ & $35.90 \pm 0.59$ \\
\hline $\operatorname{PLT}\left(10^{3} / \mu \mathrm{L}\right)$ & $847.4 \pm 300.6$ & $880.5 \pm 310.1$ & $1014.6 \pm 88.7$ & $909.7 \pm 116.2$ \\
\hline $\operatorname{Reti}\left(10^{3} / \mu \mathrm{L}\right)$ & $163.0 \pm 26.9$ & $165.0 \pm 21.6$ & $163.7 \pm 20.4$ & $135.3 \pm 25.7$ \\
\hline Reti (\%) & $2.05 \pm 0.41$ & $2.06 \pm 0.30$ & $1.99 \pm 0.27$ & $1.62 \pm 0.31^{* *}$ \\
\hline $\mathrm{PT}(\mathrm{sec})$ & $9.91 \pm 0.70$ & $9.68 \pm 0.90$ & $9.87 \pm 0.67$ & $10.35 \pm 0.61$ \\
\hline APTT (sec) & $16.28 \pm 0.62$ & $17.24 \pm 1.49$ & $16.40 \pm 1.29$ & $16.50 \pm 0.58$ \\
\hline
\end{tabular}


Table 2. Serum biochemistry results in rats exposed ethyl formate

\begin{tabular}{|c|c|c|c|c|}
\hline \multirow{2}{*}{$\begin{array}{l}\text { Parameter } \\
\text { (units of measure) }\end{array}$} & \multicolumn{4}{|c|}{ Concentration (ppm) } \\
\hline & 0 & 66 & 330 & 1320 \\
\hline \multicolumn{5}{|l|}{ Male } \\
\hline No. of animals & 10 & 10 & 10 & 10 \\
\hline AST (U/L) & $99.3 \pm 38.4$ & $85.9 \pm 13.8$ & $95.2 \pm 28.5$ & $82.4 \pm 11.7$ \\
\hline ALT (U/L) & $43.8 \pm 10.1$ & $42.6 \pm 6.3$ & $46.9 \pm 17.3$ & $45.1 \pm 6.0$ \\
\hline GGT (U/L) & $0.7 \pm 0.5$ & $0.7 \pm 0.3$ & $0.9 \pm 0.7$ & $0.7 \pm 0.7$ \\
\hline $\operatorname{ALP}(\mathrm{U} / \mathrm{L})$ & $342.2 \pm 74.4$ & $392.2 \pm 82.1$ & $322.0 \pm 30.9$ & $390.4 \pm 103.2$ \\
\hline T-Bili (mg/dL) & $0.09 \pm 0.11$ & $0.13 \pm 0.04$ & $0.14 \pm 0.03$ & $0.13 \pm 0.02$ \\
\hline Glu (mg/dL) & $140.2 \pm 17.6$ & $135.4 \pm 9.9$ & $138.0 \pm 8.3$ & $145.8 \pm 16.9$ \\
\hline $\mathrm{TP}(\mathrm{g} / \mathrm{dL})$ & $6.7 \pm 0.3$ & $6.8 \pm 0.2$ & $6.7 \pm 0.2$ & $6.6 \pm 0.2$ \\
\hline Alb (g/dL) & $4.2 \pm 0.1$ & $4.3 \pm 0.1$ & $4.3 \pm 0.2$ & $4.3 \pm 0.2$ \\
\hline $\mathrm{A} / \mathrm{G}$ ratio & $1.7 \pm 0.1$ & $1.7 \pm 0.1$ & $1.8 \pm 0.1$ & $1.8 \pm 0.1$ \\
\hline $\mathrm{TG}(\mathrm{mg} / \mathrm{dL})$ & $43.8 \pm 20.7$ & $78.6 \pm 17.8$ & $64.5 \pm 18.4$ & $35.7 \pm 13.5$ \\
\hline T-Chol (mg/dL) & $77.2 \pm 12.0$ & $84.9 \pm 13.7$ & $80.8 \pm 12.2$ & $68.2 \pm 8.9$ \\
\hline BUN (mg/dL) & $14.8 \pm 2.2$ & $14.2 \pm 1.6$ & $14.6 \pm 1.6$ & $15.5 \pm 2 . .3$ \\
\hline Crea (mg/dL) & $0.46 \pm 0.01$ & $0.45 \pm 0.01$ & $0.45 \pm 0.00$ & $0.47 \pm 0.00$ \\
\hline $\mathrm{Ca}(\mathrm{mg} / \mathrm{dL})$ & $10.2 \pm 0.2$ & $10.2 \pm 0.3$ & $10.2 \pm 0.2$ & $9.9 \pm 0.2^{* *}$ \\
\hline $\mathrm{P}(\mathrm{mg} / \mathrm{dL})$ & $6.4 \pm 0.8$ & $6.0 \pm 0.7$ & $6.3 \pm 0.8$ & $6.3 \pm 0.6$ \\
\hline $\mathrm{Na}(\mathrm{mmol} / \mathrm{dL})$ & $142.4 \pm 0.9$ & $143.4 \pm 0.5$ & $143.0 \pm 0.6$ & $143.4 \pm 1.1$ \\
\hline $\mathrm{K}(\mathrm{mmol} / \mathrm{dL})$ & $4.77 \pm 0.57$ & $4.74 \pm 0.59$ & $4.74 \pm 0.27$ & $4.65 \pm 0.34$ \\
\hline $\mathrm{Cl}(\mathrm{mmol} / \mathrm{dL})$ & $103.9 \pm 0.8$ & $104.1 \pm 1.2$ & $104.3 \pm 0.9$ & $104.7 \pm 1.1$ \\
\hline \multicolumn{5}{|l|}{ Female } \\
\hline No. of animals & 10 & 10 & 10 & 10 \\
\hline AST (U/L) & $104.1 \pm 43.3$ & $197.4 \pm 201.8$ & $98.6 \pm 25.5$ & $84.1 \pm 12.6$ \\
\hline ALT (U/L) & $54.6 \pm 21.4$ & $109.8 \pm 116.6$ & $46.3 \pm 14.0$ & $46.7 \pm 6.4$ \\
\hline GGT (U/L) & $1.4 \pm 0.8$ & $2.2 \pm 2.1$ & $1.6 \pm 0.7$ & $1.4 \pm 0.8$ \\
\hline $\operatorname{ALP}(\mathrm{U} / \mathrm{L})$ & $192.2 \pm 30.7$ & $250.2 \pm 108.2$ & $219.5 \pm 119.5$ & $257.7 \pm 73.3$ \\
\hline T-Bili (mg/dL) & $0.13 \pm 0.03$ & $0.11 \pm 0.07$ & $0.12 \pm 0.02$ & $0.12 \pm 0.02$ \\
\hline Glu (mg/dL) & $113.1 \pm 13.8$ & $121.2 \pm 8.3$ & $124.3 \pm 10.7$ & $115.0 \pm 14.2$ \\
\hline $\mathrm{TP}(\mathrm{g} / \mathrm{dL})$ & $6.8 \pm 0.5$ & $7.3 \pm 0.4$ & $6.9 \pm 0.6$ & $6.4 \pm 0.3$ \\
\hline $\mathrm{Alb}(\mathrm{g} / \mathrm{dL})$ & $4.4 \pm 0.3$ & $4.6 \pm 0.2$ & $4.4 \pm 0.4$ & $4.2 \pm 0.2$ \\
\hline $\mathrm{A} / \mathrm{G}$ ratio & $1.8 \pm 0.1$ & $1.7 \pm 0.1$ & $1.8 \pm 0.1$ & $1.9 \pm 0.1$ \\
\hline $\mathrm{TG}(\mathrm{mg} / \mathrm{dL})$ & $28.0 \pm 10.8$ & $30.7 \pm 8.6$ & $20.0 \pm 10.0$ & $14.2 \pm 7.0^{* *}$ \\
\hline T-Chol (mg/dL) & $102.3 \pm 11.2$ & $118.7 \pm 20.2$ & $94.3 \pm 22.3$ & $83.9 \pm 17.6$ \\
\hline BUN (mg/dL) & $17.6 \pm 3.6$ & $17.7 \pm 3.9$ & $17.2 \pm 1.9$ & $16.7 \pm 2.5$ \\
\hline Crea (mg/dL) & $0.44 \pm 0.05$ & $0.45 \pm 0.05$ & $0.46 \pm 0.05$ & $0.43 \pm 0.05$ \\
\hline $\mathrm{Ca}(\mathrm{mg} / \mathrm{dL})$ & $9.9 \pm 0.7$ & $10.2 \pm 0.4$ & $9.9 \pm 0.5$ & $9.6 \pm 0.3$ \\
\hline $\mathrm{P}(\mathrm{mg} / \mathrm{dL})$ & $4.9 \pm 1.2$ & $5.2 \pm 1.2$ & $5.1 \pm 1.1$ & $5.8 \pm 1.0$ \\
\hline $\mathrm{Na}(\mathrm{mmol} / \mathrm{dL})$ & $140.4 \pm 0.7$ & $139.5 \pm 1.8$ & $141.7 \pm 1.2$ & $142.1 \pm 1.3$ \\
\hline $\mathrm{K}(\mathrm{mmol} / \mathrm{dL})$ & $4.44 \pm 0.16$ & $4.75 \pm 0.62$ & $4.57 \pm 0.46$ & $4.57 \pm 0.32$ \\
\hline $\mathrm{Cl}(\mathrm{mmol} / \mathrm{dL})$ & $104.8 \pm 1.7$ & $103.7 \pm 2.1$ & $105.2 \pm 1.5$ & $106.3 \pm 1.5$ \\
\hline
\end{tabular}

**Significantly different from the control group at $p<0.01$.

Values indicate mean \pm standard deviation.

Necropsy and histopathological examination. All the macroscopic findings of the eye, liver, and ovaries were considered to be incidental and of no toxicological significance.

Degeneration was observed in 9/10 male and 10/10 female rats exposed to $1,320 \mathrm{ppm}$ and in $2 / 10$ females at 330 ppm (Fig. 3). Squamous metaplasia was observed in $2 /$ 10 male and 1/10 female rats at 1,320 ppm (Fig. 3). Morphologically, degeneration was characterized by disarrange- ment of the cellular organization, cilia loss, epithelial alteration, apoptosis, mitosis, and atrophy of the olfactory and supporting cells of the olfactory epithelium. Lesions were mainly noted in the dorsal meatus and occasionally in the septum and turbinate. All other microscopic findings were consistent with the normal background lesions in SD rats of the same age group as the rats included in the study and, therefore, were considered to be spontaneous and incidental. 
Table 3. Organ weights of rats exposed to ethyl formate

\begin{tabular}{|c|c|c|c|c|}
\hline \multirow{2}{*}{ Organ } & \multicolumn{4}{|c|}{ Concentration (ppm) } \\
\hline & 0 & 66 & 330 & 1320 \\
\hline \multicolumn{5}{|l|}{ Male } \\
\hline No. of animals & 10 & 10 & 10 & 10 \\
\hline Body weight $^{\mathrm{a})}$ (g) & $525.6 \pm 43.0$ & $543.7 \pm 28.3$ & $529.4 \pm 28.3$ & $405.1 \pm 35.7^{* *}$ \\
\hline Brain (g) & $2.18 \pm 0.09$ & $2.17 \pm 0.10$ & $2.17 \pm 0.09$ & $2.08 \pm 0.11$ \\
\hline$\%$ to body weight & $0.42 \pm 0.03$ & $0.40 \pm 0.02$ & $0.41 \pm 0.02$ & $0.52 \pm 0.05^{* *}$ \\
\hline Adrenals (g) & $0.064 \pm 0.006$ & $0.063 \pm 0.008$ & $0.068 \pm 0.011$ & $0.074 \pm 0.008^{*}$ \\
\hline$\%$ to body weight & $0.012 \pm 0.001$ & $0.012 \pm 0.001$ & $0.013 \pm 0.002$ & $0.018 \pm 0.003^{* *}$ \\
\hline Thyroid glands (g) & $0.024 \pm 0.00$ & $0.026 \pm 0.00$ & $0.025 \pm 0.01$ & $0.021 \pm 0.00$ \\
\hline$\%$ to body weight & $0.005 \pm 0.001$ & $0.005 \pm 0.001$ & $0.005 \pm 0.001$ & $0.005 \pm 0.001$ \\
\hline Heart $(\mathrm{g})$ & $1.44 \pm 0.12$ & $1.47 \pm 0.12$ & $1.45 \pm 0.11$ & $1.18 \pm 0.10^{* *}$ \\
\hline$\%$ to body weight & $0.28 \pm 0.02$ & $0.27 \pm 0.01$ & $0.27 \pm 0.01$ & $0.29 \pm 0.02$ \\
\hline Lung (g) & $1.64 \pm 0.10$ & $1.73 \pm 0.15$ & $1.81 \pm 0.27$ & $1.49 \pm 0.11^{*}$ \\
\hline$\%$ to body weight & $0.31 \pm 0.02$ & $0.32 \pm 0.02$ & $0.34 \pm 0.02$ & $0.37 \pm 0.03^{* *}$ \\
\hline Liver $(\mathrm{g})$ & $12.59 \pm 1.13$ & $13.87 \pm 1.35$ & $13.44 \pm 1.04$ & $9.98 \pm 1.19^{* *}$ \\
\hline$\%$ to body weight & $2.40 \pm 0.13$ & $2.55 \pm 0.15$ & $2.54 \pm 0.14$ & $2.46 \pm 0.14$ \\
\hline Spleen $(\mathrm{g})$ & $0.785 \pm 0.080$ & $0.835 \pm 0.088$ & $0.844 \pm 0.077$ & $0.601 \pm 0.072 * *$ \\
\hline$\%$ to body weight & $0.150 \pm 0.012$ & $0.154 \pm 0.013$ & $0.159 \pm 0.011$ & $0.148 \pm 0.009$ \\
\hline Thymus (g) & $0.391 \pm 0.082$ & $0.379 \pm 0.116$ & $0.399 \pm 0.110$ & $0.241 \pm 0.050^{* *}$ \\
\hline$\%$ to body weight & $0.074 \pm 0.013$ & $0.070 \pm 0.021$ & $0.075 \pm 0.020$ & $0.059 \pm 0.009$ \\
\hline Kidneys (g) & $3.12 \pm 0.38$ & $3.22 \pm 0.46$ & $3.03 \pm 0.27$ & $2.57 \pm 0.23 * *$ \\
\hline$\%$ to body weight & $0.59 \pm 0.05$ & $0.59 \pm 0.07$ & $0.57 \pm 0.03$ & $0.63 \pm 0.02 *$ \\
\hline Testes $(\mathrm{g})$ & $3.81 \pm 0.23$ & $3.78 \pm 0.38$ & $3.73 \pm 0.24$ & $3.61 \pm 0.18$ \\
\hline$\%$ to body weight & $0.73 \pm 0.06$ & $0.70 \pm 0.08$ & $0.71 \pm 0.06$ & $0.89 \pm 0.06^{* *}$ \\
\hline Epididymides (g) & $1.41 \pm 0.15$ & $1.39 \pm 0.11$ & $1.37 \pm 0.10$ & $1.34 \pm 0.08$ \\
\hline$\%$ to body weight & $0.27 \pm 0.03$ & $0.26 \pm 0.02$ & $0.26 \pm 0.02$ & $0.33 \pm 0.03$ \\
\hline \multicolumn{5}{|l|}{ Female } \\
\hline \multicolumn{5}{|l|}{ No. of animals } \\
\hline Body weight $^{\mathrm{a})}(\mathrm{g})$ & $252.2 \pm 21.6$ & $264.6 \pm 17.0$ & $259.1 \pm 23.1$ & $219.1 \pm 20.1^{* *}$ \\
\hline Brain $(\mathrm{g})$ & $1.98 \pm 0.08$ & $1.96 \pm 0.06$ & $1.96 \pm 0.06$ & $1.93 \pm 0.08$ \\
\hline$\%$ to body weight & $0.79 \pm 0.05$ & $0.74 \pm 0.06$ & $0.076 \pm 0.06$ & $0.89 \pm 0.07^{* *}$ \\
\hline Adrenals (g) & $0.060 \pm 0.011$ & $0.064 \pm 0.009$ & $0.066 \pm 0.006$ & $0.074 \pm 0.007^{* *}$ \\
\hline$\%$ to body weight & $0.024 \pm 0.005$ & $0.024 \pm 0.004$ & $0.026 \pm 0.003$ & $0.034 \pm 0.004^{* *}$ \\
\hline Thyroid glands (g) & $0.016 \pm 0.003$ & $0.015 \pm 0.005$ & $0.015 \pm 0.005$ & $0.013 \pm 0.005$ \\
\hline$\%$ to body weight & $0.006 \pm 0.001$ & $0.006 \pm 0.002$ & $0.006 \pm 0.002$ & $0.006 \pm 0.002$ \\
\hline Heart $(\mathrm{g})$ & $0.81 \pm 0.07$ & $0.82 \pm 0.07$ & $0.81 \pm 0.07$ & $0.70 \pm 0.07 * *$ \\
\hline$\%$ to body weight & $0.32 \pm 0.02$ & $0.31 \pm 0.02$ & $0.31 \pm 0.03$ & $0.32 \pm 0.02$ \\
\hline Lung (g) & $1.12 \pm 0.09$ & $1.16 \pm 0.11$ & $1.14 \pm 0.10$ & $1.04 \pm 0.12$ \\
\hline$\%$ to body weight & $0.45 \pm 0.02$ & $0.44 \pm 0.03$ & $0.44 \pm 0.04$ & $0.47 \pm 0.04$ \\
\hline Liver $(\mathrm{g})$ & $6.35 \pm 0.75$ & $6.91 \pm 0.56$ & $6.39 \pm 0.60$ & $5.31 \pm 0.70^{* *}$ \\
\hline$\%$ to body weight & $2.51 \pm 0.16$ & $2.61 \pm 0.16$ & $2.47 \pm 0.13$ & $2.42 \pm 0.11$ \\
\hline Spleen $(\mathrm{g})$ & $0.528 \pm 0.108$ & $0.527 \pm 0.070$ & $0.507 \pm 0.072$ & $0.393 \pm 0.061^{* *}$ \\
\hline$\%$ to body weight & $0.209 \pm 0.035$ & $0.199 \pm 0.024$ & $0.195 \pm 0.016$ & $0.179 \pm 0.018$ \\
\hline Thymus (g) & $0.281 \pm 0.041$ & $0.278 \pm 0.032$ & $0.303 \pm 0.047$ & $0.197 \pm 0.034^{* *}$ \\
\hline$\%$ to body weight & $0.112 \pm 0.021$ & $0.105 \pm 0.012$ & $0.117 \pm 0.016$ & $0.090 \pm 0.011^{* *}$ \\
\hline Kidneys (g) & $1.70 \pm 0.20$ & $1.86 \pm 0.20$ & $1.72 \pm 0.16$ & $1.52 \pm 0.15$ \\
\hline$\%$ to body weight & $0.67 \pm 0.04$ & $0.70 \pm 0.05$ & $0.66 \pm 0.05$ & $0.69 \pm 0.03$ \\
\hline Ovaries (g) & $0.081 \pm 0.014$ & $0.116 \pm 0.142$ & $0.076 \pm 0.006$ & $0.063 \pm 0.009$ \\
\hline$\%$ to body weight & $0.032 \pm 0.005$ & $0.044 \pm 0.055$ & $0.030 \pm 0.003$ & $0.029 \pm 0.004$ \\
\hline Uterus (g) & $0.608 \pm 0.164$ & $0.724 \pm 0.230$ & $0.690 \pm 0.248$ & $0.531 \pm 0.219$ \\
\hline$\%$ to body weight & $0.241 \pm 0.059$ & $0.276 \pm 0.098$ & $0.265 \pm 0.088$ & $0.243 \pm 0.100$ \\
\hline
\end{tabular}

a)The body weights were measured right before necropsy after overnight fasting.

Significantly different from vehicle control: ${ }^{*} p<0.05,{ }^{* *} p<0.01$. Values are mean \pm SD. 

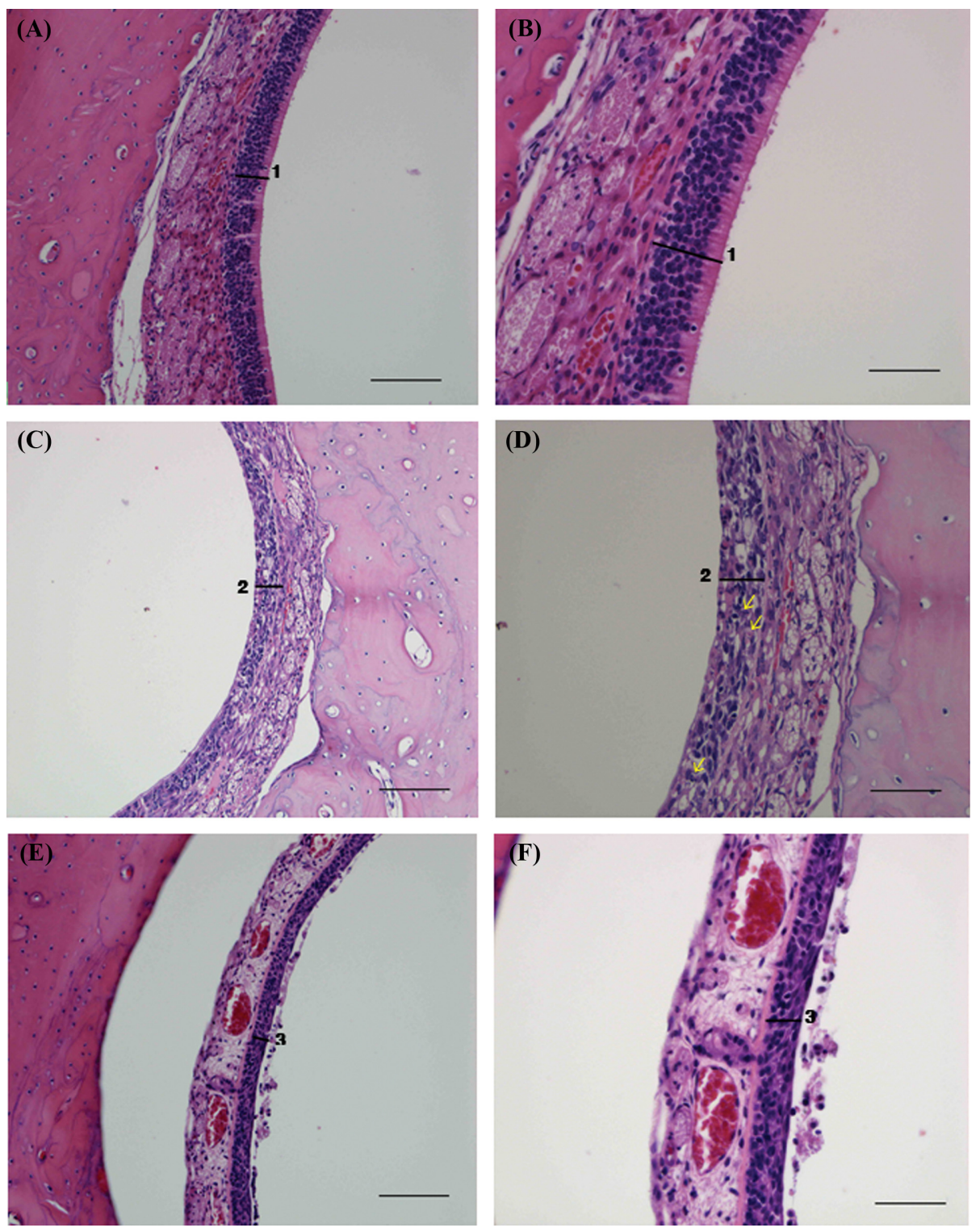

Fig. 3. Histopathological alterations in the nasopharyngeal tissue of rats exposed to (C)-(F) 1320 ethyl formate and (A), (B) control. (A), (B) Olfactory epithelium of rats exposed to fresh air was intact (for line 1) while that of rats exposed to 1,320 ppm ethyl formate showed (B), (C) degeneration characterized by cilia loss (arrow), disarrangement of the cellular organization (line 2), atrophy (line 2), and apoptosis (arrow) and (D), (F) squamous metaplasia (line 3). Magnification: (A), (C), (E) $\times 200,(B),(D),(F) \times 400$. Scale Bar (A), (C), (E) $100 \mu \mathrm{m}$, (B), (D), (F) $50 \mu \mathrm{m}$. Hematoxylin and eosin (H\&E) staining.

\section{DISCUSSION}

We evaluated the potential toxicity of ethyl formate in rats to determine its safety for long-term and low-level exposure.

Locomotor activity decreased during exposure and recovered afterward in males and females exposed to $1,320 \mathrm{ppm}$ ethyl formate, and this effect was considered an ethyl formate-related change. However, it was not considered adverse because the change was transient and noted only during exposure.
Body weight and food consumption decreased continuously in both sexes exposed to $1,320 \mathrm{ppm}$ ethyl formate from week 1 or 3 compared with the control values. The hallmarks of stress response include decreased body weight and food consumption in toxicity study (16). We hypothesized that these changes were in responses to stress. The decreased body weight and food consumption were considered to be ethyl formate-related adverse effects since the pattern was continuous and significant. The increased body weight of the male rats exposed to $330 \mathrm{ppm}$ at week 4 was not considered to be ethyl formate-related change because 
they were isolated changes.

Ketone body $(15 \mathrm{mg} / \mathrm{dL})$ levels above the control values were detected in both sexes and females exposed to 1,320 and $330 \mathrm{ppm}$ ethyl formate, respectively. Reduced body weight and food consumption are occasionally accompanied by increase in urinary ketone levels, because energy metabolism under those conditions shifts from gluconeogenesis to incomplete oxidation of fatty acids $(17,18)$. The body weight and food consumption decreased in both sexes exposed to 1,320 ppm ethyl formate. However, it was unclear whether the effect on ketone body levels was ethyl formaterelated because of the small variance and uncertain dosedependency.

Urobilinogen $(1 \mathrm{mg} / \mathrm{dL})$ levels above control values were detected in males exposed to $1,320 \mathrm{ppm}$ ethyl formate. However, this effect was not considered ethyl formaterelated because $1 \mathrm{mg} / \mathrm{dL}$ urobilinogen is regarded as the normal range according to the kit product insert.

Following the inhalation of ethyl formate $1,320 \mathrm{ppm}$, the HGB and HCT levels increased in male rats while Reti count decreased in female rats. However, these effects were not considered ethyl formate-related because no other RBCrelated changes occurred (18).

Furthermore, $\mathrm{Ca}$ and TG levels decreased in male and female rats exposed to ethyl formate $1,320 \mathrm{ppm}$, respectively. These were not considered ethyl formate-related changes owing to the small magnitude of change and absence of related alterations.

Absolute and relative increases in the adrenal weight, as well as absolute or relative decreases in the thymus weight or both were noted in rats of both sexes exposed to ethyl formate $1,320 \mathrm{ppm}$. Increased adrenal and decreased thymus weights could be regarded as a stress response based on a weight-of-evidence approach (16). These changes were accompanied by decrease in body weights and food consumption considered hallmarks of stress response. The histopathological examination did not reveal any evidence to explain the weight changes observed in the adrenal gland and thymus. Therefore, these were also considered to be ethyl formate-related and secondary to stress. The other organ weight changes were considered secondary to body weight alteration and not adverse effects.

Degeneration or squamous metaplasia of the olfactory epithelium or both in the nasopharyngeal tissue was noted in male and female rats exposed to $1,320 \mathrm{ppm}$ ethyl formate and in female rats exposed to $330 \mathrm{ppm}$. The severity of the degeneration and squamous metaplasia was minimal to mild and the affected cells were mainly supporting and olfactory cells. Inhaled and deposited material in nasal cavity could have potential toxicity in the nasal cavity (19). These were considered to be reactive and reparative responses to repeated irritation.

Taken together, our results indicate that ethyl formateinduced changes were not observed in male and female rats exposed to 330 and $66 \mathrm{ppm}$, respectively. This observation indicates that the exposure of rats to $<66 \mathrm{ppm}$ ethyl formate for 13 weeks is relatively safe. However, the reversibility of nasopharyngeal tissue injury and the effects of more prolonged exposure to ethyl formate were not confirmed in the present study. Further study is needed to confirm reversibility and chronic toxicity. Although this study has certain limitation, to the best of our knowledge, this is the first study to comprehensively repeated inhalation toxicity of ethyl formate in rats, and these results could contribute to the development of strategies for the control of occupational environmental hazards related to this substance.

\section{ACKNOWLEDGMENTS}

This work was supported by the Korea Occupational Safety and Health Agency, Ministry of Labor, Republic of Korea, and a Grant-in-Aid for chemical hazard assessment. We are grateful to all researchers who contributed to this study.

\section{CONFLICT OF INTEREST}

The authors declare that there are no conflicts of interest.

Received July 19, 2017; Revised August 25, 2017; Accepted August 29, 2017

\section{REFERENCES}

1. Desmarchelier, J.M., Johnston, F.M. and Vu, L.T. (1999) Ethyl formate, formic acid and ethanol in air, wheat, barley and sultanas: analysis of natural levels and fumigant residues. Pest Manag. Sci., 55, 815-824.

2. Haritos, V.S., Damcevski, K.A. and Dojchinov, G. (2003) Toxicological and regulatory information supporting the registration of VAPORMATE ${ }^{\mathrm{TM}}$ as a grain fumigant for farm storages in Stored Grain in Australia 2003: Proceedings of the Australian Postharvest Technical Conference, Canberra, 25-27 June 2003 (Wright, E.J., Webb, M.C. and Highley, E. Eds.). pp. 193-198.

3. Simpson, T., Bikoba, V. and Mitcham, J.E. (2004) Effects of ethyl formate on fruit quality and target pest mortality for harvested strawberries. Postharvest Biol. Technol., 34, 313-319.

4. Bell, C.H. (2000) Fumigation in the 21st century. Crop Prot., 19, 563-569.

5. Haritos, S.V., Damcevski, A.K. and Dojchinov, G. (2006) Improved efficacy of ethyl formate against stored grain insects by combination with carbon dioxide in a 'dynamic' application. Pest Manag. Sci., 62, 325-333.

6. Ciesla, Y., Rouzes, R., Fritsch, J. and Ducom, P. (2008) Efficacy of a new grain fumigant: ethyl formate/allyl isothiocyanate for the control of two stored grain beetles, the rice weevil Sitophilus oryzae L. and the granary weevil Sitophilus granarius L. IOBC/WPRS Bull., 40, 325-334. 
7. Yang, J., Park, Y., Hyun, I.-H., Kim, G.-H., Kim, B.-S., Lee, B.-H. and Ren, Y. (2016) A combination treatment using ethyl formate and phosphine to control planococcus citri (Hemiptera: Pseudococcidae) on pineapples. J. Econ. Entomol., 109, 2355-2363.

8. Sah, H. (2000) Ethyl formate - alternative dispersed solvent useful in preparing PLGA microspheres. Int. J. Pharm., 195, 103-113.

9. Health Council of the Netherlands: Committee on Updating of Occupational Exposure Limits (2002) Health-based Reassessment of Administrative Occupational Exposure Limits; Ethyl formate, Health Council of the Netherlands, The Hague, publication no. 2000/15O.

10. Occupational Safety and Health Administration. Ethyl Formate. [cited 2017 Jun 23]. Available from: https://www. osha.gov/dts/chemicalsampling/data/CH_240500.html/.

11. Ministry of Employment and Labor. Act No. 2016-41, chemical hazard information and workplace exposure limits. Available from: http://www.moel.go.kr/view.jsp?cate $=3 \&$ sec $=1 \&$ smenu $=$ $4 \&$ mode $=$ view\&bbs_cd $=116 \&$ state $=$ A\&seq $=1471867552025 /$.

12. Ku, H.R. (2000) An overview of setting occupational exposure limits (OELs) for pharmaceuticals. Chem. Health Safety, 7, 34-37.

13. European Centre for Ecotoxicology and Toxicology of Chemicals (ECETC) (2006) Technical Report No. 101: Guidance for setting occupational exposure limits: Emphasis on datapoor substances, ISSN-0773-8072-101.
14. Stoner, D.G., Shimkin, B.M., Kniazeff, J.A., Weisburger, H.J., Weisburger, K.E. and Gori, B.G. (1973) Test for carcinogenicity of food additives and chemotherapeutic agents by the pulmonary tumor response in strain A mice. Cancer Res., 33, 3069-3085.

15. Hagan, E.C., Henson, W.H., Fitzhugh, O.G., Jenner, P.M., Jones, W.I., Taylor, J.M., Long, E.L., Nelson, A.A. and Brouwer, J.B. (1967) Food flavourings and compounds of related structure. II. Subacute and chronic toxicity. Food Cosmet. Toxicol., 5, 141-157.

16. Everds, E.N., Snyder, W.P., Bailey, L.K., Bolon, B. Creasy, M.D., Foley, L.G., Rosol, J.T. and Sellers, T. (2013) Interpreting stress responses during routine toxicity studies: a review of the biology, impact, and assessment. Toxicol. Pathol., 41, 560-614.

17. Hall, R.L. (2013) Principles of clinical pathology in Toxicologic Pathology: Nonclinical Safety Assessment (Sahota, P.S., Popp, J.A., Hardisty, J.F. and Gopinatph, C. Eds.). CRC Press, India, pp. 133-173.

18. Hall, R.L. and Everds, N.E. (2014) Principles of clinical pathology for toxicology studies in Hayes' Principles and Methods of Toxicology (6th edition) (Hayes, A.W. and Kruger, C.L. Eds.). CRC Press, New York, pp. 1305-1344.

19. Kwon, S., Yang, Y.-S., Yang, H.-S., Lee, J., Kang, M.-S., Lee, B.-S., Lee, K. and Song, C.-W. (2012) Nasal and pulmonary toxicity of titanium dioxide nanoparticles in rats. Toxicol. Res., 28, 217-224. 